\title{
Analysis of muscle tone and strength and cerebral blood flow in kickboxers
}

\author{
Shevtsov A.V. ${ }^{1 \mathrm{ABCDE}}$, Sashenkov S.L. ${ }^{2 \mathrm{ABCDE}}$, Shibkova D.Z. ${ }^{3 \mathrm{ABCDE}}$, Baiguzhin P.A. ${ }^{3 \mathrm{ABCDE}}$ \\ ${ }^{1}$ Lesgaft National State University of Physical Education, Sport, and Health, Institute of Adapted Physical Education, \\ Physical Rehabilitation Department, Saint Petersburg, Russia \\ ${ }^{2}$ South Ural State Medical University, Normal Physiology Department, Chelyabinsk, Russia \\ ${ }^{3}$ South Ural State University (National Research University), Scientific and Research Center for Sports Science, \\ Institute of Sport, Tourism and Service, Chelyabinsk, Russia.
}

Authors' Contribution: A - Study design; B - Data collection; C - Statistical analysis; D - Manuscript Preparation; E - Funds Collection.

\begin{tabular}{|c|c|}
\hline \multicolumn{2}{|l|}{ Abstract } \\
\hline Purpose: & $\begin{array}{l}\text { the article deals with providing a characteristic of muscle and tone status as well as precerebral and } \\
\text { cerebral hemodynamics in kickboxers. }\end{array}$ \\
\hline Material: & $\begin{array}{l}102 \text { athletes with the qualification from the Second-class Athlete to the Master of Sport voluntary } \\
\text { participated in the study. The average age of athletes at the moment of the study was } 20.90 \pm 0.50 \text {. } \\
\text { The average sports experience of participants was equal to } 4.15 \pm 2.77 \text {. The control group consisted } \\
\text { of apparently healthy young males of the same age but not involved in sports activities ( } n=35 \text { ). The } \\
\text { indicators of muscle tone and strength and cerebral blood flow were studied with the help of Doppler } \\
\text { ultrasound of the main arteries of the head, electroneuromyography, and transcranial Doppler. }\end{array}$ \\
\hline Results: & $\begin{array}{l}\text { the article provides the results of the study on the effect of muscle and tone disturbances in the spinal } \\
\text { motion segment on the functional status of precerebral and cerebral blood flow. The disturbances in } \\
\text { nerve conduction velocity in the symmetrical groups of trunk muscles are considered as the reason for } \\
\text { muscle imbalance in } 50 \% \text { of athletes. The analysis of blood flow indicators in kickboxers with muscle } \\
\text { imbalance revealed a typical increase in the tone of precerebral vessels and changes in the gradients of } \\
\text { blood flow velocity in various segments of the carotid and vertebral arteries. The decrease of cerebral } \\
\text { blood flow in athletes, in particular, the venous outflow of a dystonic nature, is the result of spasmodic and } \\
\text { ischemic Doppler patterns against a decreased indicator of arteriovenous balance. Mild traumatic brain } \\
\text { injuries should also be taken into account when speaking about the development of cerebrovascular } \\
\text { dysfunction as a result of kickboxers' sparring activities and competitions. }\end{array}$ \\
\hline Conclusions: & $\begin{array}{l}\text { Differentiated disturbances in sensory and motor conductivity result in the disturbance of afferentation } \\
\text { and muscle imbalance intensity. Angiospasm and vascular ischemia determine the increase in the linear } \\
\text { blood flow velocity in the carotid system and the decrease in the vessels of the vertebrobasilar system } \\
\text { against the increase in resistivity indicators in the carotid basins and vertebrobasilar system in kickboxers. } \\
\text { Correlation analysis revealed visceral motor correlations, which proved the influence of the functional } \\
\text { status of the regional muscle system on cerebral hemodynamics. The analysis of tone and strength } \\
\text { muscle characteristics and cerebral blood flow in kickboxers indicates the necessity of correcting muscle } \\
\text { and tone asymmetry of the paravertebral area. }\end{array}$ \\
\hline Keywords: & electromyographic indicators, muscle imbalance, cerebral blood flow, kickboxers. \\
\hline
\end{tabular}

\section{Introduction}

Modern integral training for kickboxers includes the system of competitive exercises, which comprises acyclic, ballistic, and gravitational dynamic exercises of submaximal power. As a rule, competitive exercises are performed in an overcoming regime [1]. The effects of the methods aimed at forming the psychomotor characteristics of motor skills in kickboxers have been described [2, 3].

Monitoring technologies for establishing "the price" of body adaptation to training conditions have been developed. The information value of indicators (functional status of the cardiovascular and central nervous system, biomechanical and goniometric parameters) which determine a favorable prediction of sports performance has been established [4].

Many factors influencing directly and indirectly

\footnotetext{
c) Shevtsov A.V., Sashenkov S.L., Shibkova D.Z.

Baiguzhin P.A., 2019

doi:10.15561/18189172.2019.0507
}

precerebral and cerebral blood flow in athletes have been described in the literature. Several scientific studies dedicated to the analysis of the athletes' brain by using non-invasive, neurophysiological, and neurovisual methods $[5,6]$ emphasize a dominating contribution of the central nervous system in sports achievements.

The quality of the cognitive processing of visual, auditory, and somatosensory stimulation is determined by adaptation changes in the neural chains of the athletes' brain. It was shown that reinforced neural networks and plastic changes were the result of the integration between sensorimotor coordination, stimulus discrimination, attention, and fast decision-making [7, 8].

Mild traumatic brain injuries are quite often the result of using kicking techniques in boxing and kickboxing. According to several studies [9-11], mild traumatic brain injuries result in various pathophysiological changes. These changes in brain functioning are manifested in the following symptoms: headache, dizziness, difficulties 
with attention [11] and spatial memory in athletes [12].

However, there is no sufficient coverage for the frequency of diagnosing locomotor disturbances in apparently healthy athletes, in particular, postural muscle imbalance, muscle tone and strength disturbances, functional blockades in certain regions of the spine, etc. [13].

For a better understanding of the neurobiological mechanisms of cerebral hemodynamics, as well as their role in remodeling the structure and functions of arteries in athletes [14], it is necessary to study the correlation between the symptoms of the functional disturbances of various genesis.

The issue of the effect of muscle and tone disturbances in spine segments on central and peripheral blood flow remains relevant for sports physiology and medicine. Athletes' professional activity, especially when it comes to highly skilled wrestlers, is characterized by the specific changes in motor and visceral correlations. It is established that intensive load affects both the performance of the locomotor apparatus and functions of other visceral systems $[15,16]$. There are different reasons for locomotor tissue stress: training efforts above the threshold of athlete's abilities, a sharp increase in load intensity, changes in sports technique without body adaptation.

Locomotor tissue stress is manifested in the form of hypoxia, hypoxemia, muscular hypertonia, microcirculation disturbances, etc. [17-19]. Some studies reveal that multiyear muscle stress in the neck region results in the compression of the spinal artery and blood flow disturbances in the vertebrobasilar system.

In athletes with predominantly unilateral stress, the study of precerebral and cerebral blood flow is considered as the most important.

Aim: the study is aimed at establishing and estimating the correlation between electroneuromyographic indicators and blood flow in kickboxers.

\section{Materials and methods.}

Participants. 102 athletes with the qualification from the Second-class Athlete to the Master of Sport voluntary participated in the study. The average age of athletes at the moment of the study was $20.90 \pm 0.50$. The average sports experience of participants was equal to $4.15 \pm 2.77$. The control group consisted of apparently healthy young males of the same age but not involved in sports activities $(\mathrm{n}=35)$.

\section{Research Design.}

Electroneuromyography. Tone and strength characteristics, as well as the speed of excitation propagation in motor and sensory fibers, were estimated with the help of Neuromatic 2000 equipment (Dantec, Denmark). The indicators of surface electromyogram (EMG) in all participants corresponded to type I in compliance with Yusevich Yu. [20]. EMG with an amplitude of more than $300 \mathrm{mkV}$ was recorded. A direct proportional dependence was registered between muscle power and the EMG amplitude of maximal voluntary effort. Qualitative and quantitative EMG assessment in various spine segments at maximal stress revealed asymmetrical amplitude indicators typical for muscle imbalance.

Doppler ultrasonography. Both the US Doppler of the main arteries of the head and transcranial Doppler were conducted by using «Smart-lite» (Rimad, Israel) equipment with color flow mapping and the automatic recording of microembolic signals. The insonation of proximal and distal segments of the common carotid artery, subclavian arteries, the internal and external carotid artery, the vertebral artery in three segments at the extracranial level was conducted with the help of transmitters with a generated frequency of US signal of 2.4 MHz. The transcranial study was accompanied by the insonation of the vessels of the carotid basin - anterior, middle, and posterior left and right brain arteries - and vertebrobasilar vessels - left and right vertebral arteries ( $4^{\text {th }}$ segment) and the main (basilar) artery. Tables demonstrate the values of the linear blood flow velocity (LBFV), Pourcelot resistivity index (RI), and carotid gradients of the common carotid artery (CCA), internal carotid artery (ICA), external carotid artery (ECA), right and left vertebral arteries of the first and second segments (LVA1, LVA2, RVA1, RVA2), posterior, middle, and anterior brain arteries (PBA, MBA, ABA), main (basilar) artery.

Statistical Analysis. Statistical calculations were performed in the SPSS 12.1 licensed program. The data are provided in averaged values. To reveal correlations and their character, we used correlation analysis (r).

\section{Results.}

The analysis of the background ENMG muscle parameters.

In kickboxers, we revealed a decreased speed of excitation propagation in afferent and efferent fibers compared to standard values. In the majority of the athletes $(90.72 \%)$, we also revealed Grade I sensory conductivity disturbances. The decrease in this indicator did not exceed $25.0 \%$ compared to standard values. Almost half of the kickboxers (45.36\%) demonstrated a mild disturbance of conductivity in motor fibers. Deviations were up to $15.0 \%$ from standard values with no clinical signs. $42.27 \%$ of the sample had a simultaneous conductivity disturbance in the sensory and motor fibers of peripheral nerves. The subclinical signs of sensory polyneuropathy were registered in $37.11 \%$ of kickboxers, motor polyneuropathy - in $3.09 \%$.

We performed a quantitative assessment of tension amplitudes in certain groups of muscles. In $20.0 \%$ of the kickboxers, we registered a homogeneous distribution of tone in posterior neck muscles (deep neck extensors). Increased muscle tone on the right side was revealed in $31.4 \%$ of the sample, on the left side - in $48.6 \%$. The analysis of amplitude asymmetry and imbalance in the symmetrical areas of muscles on the right and the left side revealed that, in $60.0 \%$ of the athletes, the imbalance was up to $50.0 \%$. For example, the asymmetry of tension 
amplitude in the trapezius muscle on the right and the left side was equal $48.0 \%$. The same tendency was registered in the group of muscles responsible for the spine extension in the thoracic spine area. The absence of muscle imbalance was revealed only in $28.0 \%$.

Significant quantitative changes were revealed in the area of the lumbar spine. The increased tone in the muscles on the right side was registered in $25.7 \%$ of the athletes, on the left side - in $45.7 \%$, the absence of the pronounced asymmetry in muscle tone was established in $28.6 \%$. The intensity of changes in the area of the lumbar spine differed compared to the areas above this region: we registered a muscle imbalance of up to $50.0 \%$ in $89.0 \%$ of the athletes and up to $70.0 \%$ in $11.0 \%$.

Precerebral and cerebral blood flow in kickboxers. Table 1 demonstrates the linear blood flow velocity (LBFV), Pourcelot resistivity index (RI) of precerebral vessels, and the segmental assessment of vertebral arteries. The increased values of blood flow velocity in the carotid and vertebral arteries on the right and the left side are the result of an increase in systolic (LBFV syst.) and decrease in diastolic (LBFV diast.) blood flow velocity. The gradient between the common carotid and internal carotid arteries exceeded the reference values and was equal to 1.56-1.62 c.u.; the gradient between the internal and external carotid arteries was below reference values $-0.78-0.86$ c.u.

To reveal latent disturbances in the hemodynamics of the vertebrobasilar system, we studied blood flow indicators in all segments of the vertebral arteries - I, II, III - at the extracranial and the intracranial level (IV) at the initial state and under contralateral rotation. Table 1 shows that the vertebral gradient in kickboxers was $73.0 \%$ higher compared to the control group.

The analysis of cerebral hemodynamics in kickboxers revealed relatively high values (by $32-45 \%$ ) of the systolic linear blood flow velocity compared to the control values for all cerebral arteries (right-left). In vertebral arteries,

Table 1. Precerbral blood flow indicators in the sample studied ( $M \pm m$ )

\begin{tabular}{|c|c|c|}
\hline Extracranial Doppler data, c.u. & $\begin{array}{l}\text { Control group } \\
(n=35)\end{array}$ & $\begin{array}{l}\text { Kickboxers } \\
(n=102)\end{array}$ \\
\hline LBFV right common carotid artery, $\mathrm{cm} / \mathrm{s}$ & $96.02 \pm 25.10$ & $123.20 \pm 17.50 *$ \\
\hline RI right common carotid artery, c.u. & $0.72 \pm 0.06$ & $0.89 \pm 0.05^{*}$ \\
\hline Carotid gradient on the right side CCA/ICA & $1.32 \pm 0.12$ & $1.56 \pm 0.29$ \\
\hline LBFV right internal carotid artery, $\mathrm{cm} / \mathrm{s}$ & $66.80 \pm 17.90$ & $75.90 \pm 15.46^{*}$ \\
\hline RI right internal carotid artery, c.u. & $0.60 \pm 0.07$ & $0.77 \pm 0.08 *$ \\
\hline Carotid gradient on the right side ICA/ECA & $1.12 \pm 0.17$ & $0.78 \pm 0.23 *$ \\
\hline LBFV right external carotid artery, cm/s & $63.00 \pm 17.00$ & $95.68 \pm 13.25^{*}$ \\
\hline RI right external carotid artery, c.u. & $0.79 \pm 0.15$ & $0.88 \pm 0.07^{*}$ \\
\hline LBFV right vertebral artery, segment $1, \mathrm{~cm} / \mathrm{s}$ & $48.00 \pm 10.00$ & $57.91 \pm 15.53^{*}$ \\
\hline RI right vertebral artery, segment 1, c.u. & $0.66 \pm 0.07$ & $0.84 \pm 0.19 *$ \\
\hline LBFV right vertebral artery, segment $2, \mathrm{~cm} / \mathrm{s}$ & $45.10 \pm 9.11$ & $42.51 \pm 16.35$ \\
\hline RI right vertebral artery, segment 2, c.u. & $0.64 \pm 0.06$ & $0.78 \pm 0.20 *$ \\
\hline LBFV right vertebral artery, segment $3, \mathrm{~cm} / \mathrm{s}$ & $49.25 \pm 11.20$ & $54.56 \pm 17.03^{*}$ \\
\hline RI right vertebral artery, segment 3, c.u. & $0.58 \pm 0.05$ & $0.78 \pm 0.13^{*}$ \\
\hline Carotid gradient on the right side RVA-RVA2/RVA2, \% & $9.66 \pm 0.05$ & $40.41 \pm 19.46^{*}$ \\
\hline LBFV left common carotid artery, $\mathrm{cm} / \mathrm{s}$ & $96.00 \pm 17.5$ & $131.80 \pm 16.3^{*}$ \\
\hline RI left common carotid artery, c.u. & $0.72 \pm 0.06$ & $0.90 \pm 0.06^{*}$ \\
\hline Carotid gradient on the left side CCA/ICA & $1.44 \pm 0.19$ & $1.62 \pm 0.21 *$ \\
\hline LBFV left internal carotid artery, cm/s & $66.80 \pm 19.90$ & $79.75 \pm 16.51^{*}$ \\
\hline RI left internal carotid artery, c.u. & $0.60 \pm 0.09$ & $0.77 \pm 0.05^{*}$ \\
\hline Carotid gradient on the left side ICA/ECA & $1.05 \pm 0.17$ & $0.86 \pm 0.24$ \\
\hline LBFV left external carotid artery, $\mathrm{cm} / \mathrm{s}$ & $64.00 \pm 17.00$ & $98.02 \pm 14.55^{*}$ \\
\hline RI left external carotid artery, c.u. & $0.79 \pm 0.15$ & $0.89 \pm 0.08^{*}$ \\
\hline LBFV left vertebral artery, segment $1, \mathrm{~cm} / \mathrm{s}$ & $50.12 \pm 10.0$ & $59.58 \pm 13.92 *$ \\
\hline RI left vertebral artery, segment 1, c.u. & $0.67 \pm 0.05$ & $0.78 \pm 0.07^{*}$ \\
\hline LBFV left vertebral artery, segment $2, \mathrm{~cm} / \mathrm{s}$ & $46.00 \pm 10.00$ & $40.82 \pm 13.27$ \\
\hline RI left vertebral artery, segment 2, c.u. & $0.56 \pm 0.06$ & $0.80 \pm 0.06^{*}$ \\
\hline LBFV left vertebral artery, segment $3, \mathrm{~cm} / \mathrm{s}$ & $43.10 \pm 9.11$ & $59.46 \pm 13.30 *$ \\
\hline RI left vertebral artery, segment 3, c.u. & $0.60 \pm 0.06$ & $0.84 \pm 0.14^{*}$ \\
\hline Carotid gradient on the left side LVA1-LVA2/LVA2, \% & $8.69 \pm 8.20$ & $52.50 \pm 20.97 *$ \\
\hline
\end{tabular}

Note: * differences between the indicators of the groups $(p<0.05)$ 
we revealed a decrease in the linear blood flow by 52$75 \%$. The resistivity index was increased in all large arteries.

We also analyzed a decrease in the linear blood flow velocity in the vessels of the brain. In general, we studied 9 cerebral vessels in each participant. Table 2 shows that, in kickboxers, approximately $22.0 \%$ of the vessels, mostly vertebral arteries, possessed the signs of a decrease in the linear blood flow velocity. In case of a unilateral lesion, the signs of a decrease in the linear blood flow velocity were mostly typical for the right vertebral artery.

We established that, in athletes, the asymmetry of blood flow in middle brain arteries was 3 times higher and 2 times exceeded the asymmetry in anterior brain arteries, 5 times - posterior brain arteries, 10 times - vertebral arteries compared to the reference values.

The most frequent patterns in athletes were spasmodic (increased LBFV, decreased RI - 28.5\%) and ischemic (decreased LBFV, decreased RI - 34.4\%). The third place belonged to the hyperemic pattern (increased LBFV, decreased RI - 17.6\%) which preceded the spasmodic one.

In kickboxers, the blood flow velocity in the basal vein of Rosenthal exceeded the reference values by $37.0 \%$. The arteriovenous balance indicator was lower than 1 , which identifies difficulties of dystonic nature with the venous outflow (Table 3 ).

We studied such reserves of brain blood flow regulation as anatomic, myogenic, and metabolic. In all participants, we studied the system of arteries of the Willis' circle, which combines anatomically 2 systems of carotid arteries with each other and with the system of vertebral arteries.

The analysis of the Willis' circle revealed that, in the

Table 2. Cerebral blood flow indicators in the sample studied ( $\mathrm{M} \pm \mathrm{m})$

\begin{tabular}{lll}
\hline Cerebral blood flow indicators & Control group ( $\mathbf{n = 3 5}$ ) & Kickboxers ( $\mathbf{n = 1 0 2 )}$ \\
\hline LBFV right middle cerebral artery, cm/s & $94.7 \pm 19.5$ & $137.4 \pm 17.9^{*}$ \\
RI right middle cerebral artery, c.u. & $0.55 \pm 0.08$ & $0.63 \pm 0.05^{*}$ \\
LBFV right anterior cerebral artery, cm/s & $76.4 \pm 19.0$ & $86.93 \pm 22.76^{*}$ \\
RI right anterior cerebral artery, c.u. & $0.58 \pm 0.02$ & $0.68 \pm 0.06^{*}$ \\
LBFV left middle cerebral artery, cm/s & $95.7 \pm 19.5$ & $125.15 \pm 18.4^{*}$ \\
RI left middle cerebral artery, c.u. & $0.54 \pm 0.16$ & $0.74 \pm 0.05^{*}$ \\
LBFV left anterior cerebral artery, cm/s & $77.5 \pm 17.4$ & $82.62 \pm 16.61$ \\
RI left anterior cerebral artery, c.u. & $0.53 \pm 0.18$ & $0.65 \pm 0.05^{* *}$ \\
Interhemispheric asymmetry by MBA, \% & $4.1 \pm 1.3$ & $11.93 \pm 10.5^{*}$ \\
Interhemispheric asymmetry by ABA, \% & $2.5 \pm 1.3$ & $4.5 \pm 0.5^{*}$ \\
LBFV right posterior cerebral artery, cm/s & $53.2 \pm 16.2$ & $77.85 \pm 11.6^{*}$ \\
RI right posterior cerebral artery, c.u. & $0.55 \pm 0.15$ & $0.74 \pm 0.05^{*}$ \\
LBFV left posterior cerebral artery, cm/s & $55.4 \pm 15.1$ & $63.12 \pm 9.99^{*}$ \\
RI left posterior cerebral artery, c.u. & $0.55 \pm 0.12$ & $0.74 \pm 0.06^{*}$ \\
Interhemispheric asymmetry by PBA, \% & $3.8 \pm 2.1$ & $17.5 \pm 15.5^{*}$ \\
LBFV right vertebral artery, segment 4, cm/s & $56.6 \pm 7.5$ & $32.87 \pm 11.59^{*}$ \\
RI right vertebral artery, segment 4, c.u. & $0.52 \pm 0.06$ & $0.59 \pm 0.05$ \\
LBFV left vertebral artery, segment 4, cm/s & $55.2 \pm 3.5$ & $36.72 \pm 12.47^{*}$ \\
RI left vertebral artery, segment 4, c.u. & $0.52 \pm 0.12$ & $0.65 \pm 0.06^{*}$ \\
Interhemispheric asymmetry by vertebral arteries, \% & $1.2 \pm 1.1$ & $12.5 \pm 8.5^{*}$ \\
LBFV of the main (basilar) artery, cm/s & $58.0 \pm 11.0$ & $73.34 \pm 13.86$ \\
RI of the main (basilar) artery, c.u. & $0.50 \pm 0.04$ & $0.63 \pm 0.06^{*}$ \\
\hline
\end{tabular}

Note: * - differences between the indicators of the groups $(p<0.05)$

Table 3. Regulation reserves and venous outflow of the sample $(M \pm m)$

\begin{tabular}{lll}
\hline Parameter & $\begin{array}{l}\text { Control group } \\
(\mathbf{n = 3 5 )}\end{array}$ & $\begin{array}{l}\text { Kickboxers } \\
(\mathbf{n = 1 0 2})\end{array}$ \\
\hline Willis' circle (\% disconnection) & 57.10 & 36.20 \\
Autoregulatory response (myogenic reserve) \% & $74.00 \pm 1.50$ & $65.11 \pm 19.10^{*}$ \\
Metabolic reserve (Cerebrovascular Reactivity Index), \% & $51.20 \pm 1.60$ & $28.55 \pm 11.63$ \\
Basal vein of Rosenthal (LBFV), cm/s & $19.00 \pm 1.30$ & $26.48 \pm 5.82^{*}$ \\
Arteriovenous balance & $1.00 \pm 0.50$ & $0.76 \pm 0.34^{*}$ \\
\hline
\end{tabular}

Note: * differences between the indicators of the groups $(p<0.05)$ 
control group, $52.6 \%$ of the students were characterized by the typical functioning of the circle when after the compression of the carotid artery all communicating arteries performed their work. In kickboxers, the same functioning was registered in $36.2 \%$ of the sample.

To reveal correlations between the main parameters determining the neuromuscular apparatus, as well as precerebral and cerebral blood flow in kickboxers, we performed correlation analysis. The most informative parameter was the carotid gradient on the right side (CCA/ ICA). This parameter possessed statistically significant correlations with seven electroneuromyographic parameters. CCA/ICA, Resistivity Index (the right internal carotid artery), and the vertebral gradient on the right side (RVA1-RVA2/RVA2) demonstrated a less number of correlations. For example, the value of the vertebral gradient on the left side is connected with three parameters, while the linear blood flow velocity in the right carotid artery is connected with two parameters (Table 4).

It should be noticed that various parameters of the neuromuscular apparatus contribute differently to cerebral blood flow.

\section{Discussion.}

The disturbances established in the speed of excitation propagation (SEP) could be the reason for the muscular imbalance in kickboxers as a result of specific physical load.

The analysis of the general amplitude asymmetry and imbalance in the symmetrical areas of muscles on the left and the right side revealed that the majority of athletes was characterized by the imbalance of $50 \%$. The subclinical signs of sensory polyneuropathy were registered in onethird of the kickboxers. There were also a few cases of motor polyneuropathy.

The study of blood flow in kickboxers with muscular imbalance revealed a typical increase in the tone of precerebral vessels and the changes in the gradients of the blood flow velocity in various segments of carotid and vertebral arteries.

Similar results have been previously described by H.B. Liu [14] in the study of precerebral hemodynamics in basketball players. The authors identify the differences in the Doppler patterns obtained in athletes and the control group both at the initial state and after dosed cyclic load. In particular, the oscillation shear index (OSI) in athletes is higher than in the control group.

The results obtained in our study prove the increase in the tone of large and small arteries as a protective mechanism for a hyperkinetic type of central hemodynamics.

In athletes, we revealed a blood flow asymmetry of a various degree in middle brain arteries. The increase in the coefficient of asymmetry in the vessels of the vertebrobasilar basin can be possibly explained by the reflectory effect of tensed muscles on the sympathetic plexus of vertebral arteries. A system vascular resistance decreases under physical load as a result of metabolismrelated vasodilatation in active skeletal muscles [21]. This vasodilation provoked by physical exercises is closely connected with a decrease in oxygen tension in the muscular tissue and is characterized by a decreased response to adrenergic vasoconstrictor mechanisms [22].

The spasmodic and ischemic patterns revealed in athletes against a decreased value of arteriovenous

Table 4. Correlations between the ENMG parameters and cerebral blood flow in kickboxers

\begin{tabular}{|c|c|c|c|c|c|c|}
\hline Parameter & $\begin{array}{l}\text { LBFV } \\
\text { right } \\
\text { common } \\
\text { carotid } \\
\text { artery } \\
\end{array}$ & $\begin{array}{l}\text { Vertebral } \\
\text { gradient on } \\
\text { the left side } \\
\text { (LVA1-LVA2/ } \\
\text { LVA2) }\end{array}$ & $\begin{array}{l}\text { Carotid } \\
\text { gradient } \\
\text { on the } \\
\text { right side } \\
\text { (CCA/ICA) }\end{array}$ & $\begin{array}{l}\text { RI right } \\
\text { internal } \\
\text { carotid } \\
\text { artery }\end{array}$ & $\begin{array}{l}\text { Vertebral } \\
\text { gradient on } \\
\text { the right side } \\
\text { (RVA1-RVA2/ } \\
\text { RVA2) }\end{array}$ & $\begin{array}{l}\text { Carotid } \\
\text { gradient } \\
\text { on the left } \\
\text { side (CCA/ } \\
\text { ICA) }\end{array}$ \\
\hline SEP in motor (efferent) fibers & & & -0.52 & & & \\
\hline $\begin{array}{l}\text { SEP in sensory (afferent) } \\
\text { fibers }\end{array}$ & & -0.43 & & & 0.73 & \\
\hline $\begin{array}{l}\text { Total EMG amplitude m. } \\
\text { longissimus thoracic }\end{array}$ & & & & 0.39 & & \\
\hline $\begin{array}{l}\text { Total EMG amplitude m. } \\
\text { Trapezius }\end{array}$ & & & -0.42 & 0.37 & & 0.57 \\
\hline M-response amplitude & & & -0.44 & 0.40 & & \\
\hline M-response duration & & & -0.32 & & 0.34 & 0.38 \\
\hline $\begin{array}{l}\text { m. Trapezius amplitude } \\
\text { imbalance }\end{array}$ & & & -0.37 & & & 0.40 \\
\hline $\begin{array}{l}\text { T4- } 5 \text { trunk erector amplitude } \\
\text { imbalance }\end{array}$ & -0.48 & 0.40 & -0.37 & -0.30 & 0.35 & 0.43 \\
\hline $\begin{array}{l}\text { T12 trunk erector amplitude } \\
\text { imbalance }\end{array}$ & 0.49 & -0.40 & -0.57 & 0.61 & -0.37 & -0.33 \\
\hline
\end{tabular}

Note: only statistically significant correlations are given. 
balance (below 1 c.u.) proved an obstructed venous outflow of dystonic nature which should be regarded as a reason of cerebral blood flow worsening. The spasmodic reaction, participating in blood flow regulation, is based on two potential mechanisms: dehydration as a result of electrolyte exhaustion and a neuromuscular mechanism [23].

The study of precerebral and cerebral hemodynamics allows estimating the mechanisms of anatomic, myogenic, and metabolic reserves in cerebral blood flow regulation $[24,25]$. The literature provides the data on the effect of circulating hormones on cerebral blood flow regulation, in particular, on changes in the tone of brain vessels depending on the concentration of blood melatonin and estrogen/testosterone [26].

The study of R.M.G. Berg [27] demonstrates that metabolic feedback is faster than a myogenic one. The first one initiates a cerebral autoregulatory response, while myogenic feedback contains a relatively slower mechanism which functions for establishing basal cerebrovascular tone. Nevertheless, the myogenic factor (as well as metabolic and baroreflexive) is the leading factor in vascular tone regulation [28].

To study myogenic mechanisms in cerebral blood flow regulation against a decrease in perfusion pressure, we used carotid artery compression. As a rule, carotid artery compression provokes the autoregulatory reaction compensating cerebral blood flow deficiency. This results in the dilation of the pial arteries and activation of anastomoses of a convex cerebral surface. The linear blood flow velocity in the middle cerebral artery decreases to not less than $50-70 \%$. Carotid artery deocclusion results in the increase of the linear blood flow velocity above the initial level proportionally to the time of compression (reactive hyperemia).

The analysis of the remaining linear blood flow velocity ( $\%$ to initial LBFV) in the basin of the main carotid revealed standard values for a myogenic reserve in the control group $-74.00 \% \pm 1.50 \%$. These values were $15 \%$ less in athletes with muscular imbalance $65.11 \pm 19.03 \%$

Peripheral blood flow is regulated by the balance between the mechanisms responsible for vasodilation and vasoconstriction. Free radicals, by-products considered as toxic in vivo, are recognized as important signal molecules which provide vasoactive responses [22].

It is also necessary to take into account the mechanism of the development of cerebrovascular dysfunction as a result of traumatic brain injury provoked by kicking technique during sparring activities and competitions [11, 29].

Studies of the relationship between peripheral blood biomarkers and the results of cerebral hemodynamics are of practical significance [30, 31]. Changes in cerebral blood flow are associated with the concentration of PRDX-6 and T-Tau proteins in the blood (MAPT). Increased MAPT concentrations in the CNS and blood are associated with axonal damage. In particular, an increase in MAPT was observed in the blood of Olympic boxers even after a slight head injury suggesting minor CNS damage [32].

According to E.D. Bell et al. [33], traumatic brain injuries usually result in autoregulatory dysfunction associated with the inability of cerebral vessels to maintain homeostasis. The authors argue that cerebrovascular autoregulatory dysfunction does not depend on the chemical environment in the brain tissues against or after traumatic brain injury.

Thus, reduced cerebral blood flow may be associated with oxidative stress being the result of cranial and cerebral injuries caused by shock and other factors. It should be noticed that physiological disorders caused by reduced cerebral blood flow can often be latent in their clinical course [30].

The results obtained during the study can be used in sports physiology and sports medicine, as well as in rehabilitation and health facilities for the prevention and treatment of myofascial dysfunctions and vertebral disorders in martial arts athletes.

\section{Conclusions.}

1. Kickboxers are characterized by the disturbance in a functionally significant muscle group manifested in increasing or decreasing tone and muscle imbalance. Differentiated disorders of sensory and motor conductivity lead to impaired afferentation and pronounced muscle imbalance.

2. Kickboxers with muscular imbalance provoked by the intensive physical load are characterized by the disturbances in pre-cerebral and cerebral hemodynamics. Angiospasm and vascular ischemia determine the increase in the linear blood flow velocity in the carotid system and the decrease in the vessels of the vertebrobasilar system against the increase in resistivity indicators in the carotid basins and vertebrobasilar system in kickboxers.

3. Correlation analysis revealed visceromotor connections proving the influence of the functional status of the regional muscular system on the cerebral hemodynamics.

4. Analysis of the muscle tone and strength characteristics, cerebral blood flow, and the speed of excitation propagation in kickboxers indicates the need for correcting the muscle and tone asymmetry of the paravertebral zone.

\section{Conflict of interests}

The authors declare that there is no conflict of interests. 


\section{References}

1. Romanov YuN, Mokeev GI. Linear indicators of a cerebral blood flow depending on sample differences of a hemodynamics and asymmetry in the system of integrated training of kickboxers. Scientific notes of the university of P.F. Lesgaft. 2013;1(95):128-134. (in Russian) https://doi.org/10.5930/issn.1994-4683.2013.01.95.p128134

2. Markov KK. Perfection of the technique of formation psychomotor characteristics of motor skills in highly skilled kickboxers. Modern high technologies. 2015;12-1:118-121. (in Russian)

3. Chechev IS. Improved temporal perception of highly trained kickboxers. Modern high technologies. 2016;8-1:163-167. (in Russian)

4. Podrigalo LV, Volodchenko AA, Rovnaya OA, Podavalenko OV, Grynova TI. The prediction of success in kickboxing based on the analysis of morphofunctional, physiological, biomechanical and psychophysiological indicators. Physical education of students. 2018;22(1):51-56. https://doi.org/10.15561/20755279.2018.0108

5. Murrell CJ, Cotter JD, George K, Shave R, Wilson L, Thomas K, Williams MJA., Ainslie PN. Cardiorespiratory and cerebrovascular responses to head-up tilt II: Influence of age, training status and acute exercise. Experimental Gerontology. 2011;46(1):1-8. https://doi.org/10.1016/j.exger.2010.06.004

6. Opondo MA, Sarma S, Levine BD. The Cardiovascular Physiology of Sports and Exercise. Clinics in Sports Medicine. 2015;34(3):391-404. https://doi.org/10.1016/j.csm.2015.03.004

7. Nakata H, Yoshie M, Miura A, Kudo K. Characteristics of the athletes' brain: Evidence from neurophysiology and neuroimaging. Brain Research Reviews. 2010;62(2):197-211. https://doi.org/10.1016/j.brainresrev.2009.11.006

8. Wolff W, Thürmer JL, Stadler K-M, Schüler J. Ready, set, go: Cortical hemodynamics during self-controlled sprint starts. Psychology of Sport and Exercise. 2019;41:21-28. https://doi.org/10.1016/j.psychsport.2018.11.002

9. Sawauchi S, Terao T, Tani S, Ogawa $T$, Abe $T$. Traumatic middle cerebral artery occlusion from boxing. Journal of Clinical Neuroscience. 1999;6(1):63-66. https://doi.org/10.1016/S0967-5868(99)90610-0

10.Coletta DF. Nonneurologic Emergencies in boxing. Clinics in Sports Medicine. 2009;28(4):579-590. https://doi.org/10.1016/j.csm.2009.06.001

11.McCrory P, Feddermann-Demont N, Dvoøák J, Cassidy JD, McIntosh A, Vos PE, Echemendia RJ,Meeuwisse W,Tarnutzer AA.What is the definition of sports-related concussion: A systematic review (Review). British Journal of Sports Medicine. 2017;51(11):877-887. https://doi.org/10.1136/bjsports-2016-097393

12.Slobounov SM, Zhang K, Pennell D, Ray W, Johnson B, Sebastianelli W. Functional abnormalities in normally appearing athletes following mild traumatic brain injury: a functional MRI study. Experimental Brain Research. 2010;202(2):341-354. https://doi.org/10.1007/s00221-009-2141-6

13. Nealon AR, Kountouris A, Cook JL. Side strain in sport: a narrative review of pathomechanics, diagnosis, imaging and management for the clinician. Journal of Science and Medicine in Sport. 2017;20(3):261-266. https://doi.org/10.1016/j.jsams.2016.08.016

14.Liu HB, Yuan WX, Qin KR, Hou J. Acute effect of cycling intervention on carotid arterial hemodynamics: basketball athletes versus sedentary controls.
Bio Medical Engineering On Line. 2015;14:S17. https://doi.org/10.1186/1475-925X-14-S1-S17

15.Sternin YuI. Adaptation and after treatment in elite sport: Monograph. SPb, 2008. (in Russian)

16.Fudin NA, KlassinaSYa, Pigareva SN. Interrelation of indicators of muscular and cardiovascular systems at the increasing exercisestress at the personsplaying physicalculture and sport. Human Physiology. 2015;41(4):82. (in Russian) https://doi.org/10.1134/S0362119715040088

17.Romanov YuN, Isaev AP. Physiological justification of integrated preparation in kickboxing. Scientific notes of the university of P.F. Lesgaft. 2013;2(96):144-149. (in Russian) https://doi.org/10.5930/issn.1994-4683.2013.02.96.p144149

18.Balykova LA, Ivyanskij SA, Gromova EV, Varlashina KA, Shchyokina NV, Davydov PA. Pathogenetic aspects of formation of the dezadaptatsionny changes of cardiovascular system mediated by exercise stresses. Bulletin of the Mordovian university. 2016;26(3):336-348. (in Russian) https://doi.org/10.15507/0236-2910.026.201603.336-348

19.Tupiev ID, Latukhov SV, Shibkova DZ. Physiological effects of using physical loads of different intensity in female students aged 21-23. Theory and Practice of Physical Culture. 2014;10:17.(in Russian)

20.Yusevich YuS. Electromyography in the clinic of nervous diseases. Moscow; 1958. (in Russian)

21.Hogan TS. Exercise-induced reduction in systemic vascular resistance: A covert killer and an unrecognised resuscitation challenge? Medical Hypotheses. 2009;73(4):479-484. https://doi.org/10.1016/j.mehy.2009.06.021

22.Trinity JD, Broxterman RM, Richardson RS. Regulation of exercise blood flow: Role of free radicals. Free Radical Biology and Medicine. 2016;98:90-102. https://doi.org/10.1016/j.freeradbiomed.2016.01.017.

23.Giuriato G, Pedrinolla A, Schena F, Venturelli M. Muscle cramps: A comparison of the two-leading hypothesis. Journal of Electromyography and Kinesiology. 2018;41:89-95. https://doi.org/10.1016/j.jelekin.2018.05.006

24.Moskalenko YuE, Weinstein GB. Development of Current Concepts of Physiology of Cerebral Circulation: A Comparative Analysis.Journal of Evolutionary Biochemistry and Physiology. 2001;37(5):492-506. https://oi.org/10.1023/A:1014074328113

25.Mulliri G, Sainas G, Magnani S, Roberto S, Ghiani G, Mannoni M, Pinna V, Willis SJ, Millet GP, Doneddu A, Crisafulli A. Effects of exercise in normobaric hypoxia on hemodynamics during muscle metaboreflex activation in normoxia. European Journal of Applied Physiology. 2019:1-12. https://doi.org/10.1007/s00421-019-04103-y

26.Krause DN, Geary GG, McNeill AM, Ospina J, Duckles SP. Impact of hormones on the regulation of cerebral vascular tone. International Congress Series. 2002;1235:395-399. https://doi.org/10.1016/S0531-5131(02)00211-X

27.Berg RMG. Myogenic and metabolic feedback in cerebral autoregulation: Putative involvement of arachidonic aciddependent pathways. Medical Hypotheses. 2016;92:12-17. https://doi.org/10.1016/j.mehy.2016.04.024

28.Keijsers JMT, Leguy CAD, Narracott AJ, Rittweger $\mathrm{J}$, Vosse FN, Huberts W. Modeling regulation of vascular tone following muscle contraction: Model development, validation and global sensitivity analysis. Journal of Computational Science. 2018;24:143-159. https://doi.org/10.1016/j.jocs.2017.04.007

29.Sorond F, Frantz J, Bell K, Hynan L, Purkayastha S, Sabo T. Cerebral vasoreactivity is impaired three month following sports-related concussion in 
collegiate athletes. Archives of Physical Medicine and Rehabilitation, 2018;99(11):e130-e131. https://doi.org/10.1016/j.apmr.2018.08.010

30.Battista AP, Churchill N, Schweizer TA, Rhind SG, Richards D, Baker AJ, Hutchison MG. Blood biomarkers are associated with brain function and blood flow following sport concussion. Journal of Neuroimmunology. 2018;319:1-8. https://doi.org/10.1016/j.jneuroim.2018.03.002

31.Sankar SB, Pybus AF, Liew A, Sanders B, Buckley EM. Low cerebral blood flow is a non-invasive biomarker of neuroinflammation after repetitive mild traumatic brain injury. Neurobiology of Disease.2019;124:544-554. https://doi.org/10.1016/j.nbd.2018.12.018.

32.Olczak M, Niderla-Bielińska J, Kwiatkowska M, Samojłowicz D, Tarka S, Wierzba-Bobrowicz T. Tau protein (MAPT) as a possible biochemical marker of traumatic brain injury in postmortem examination. Forensic Science International. 2017;280:1-7. https://doi.org/10.1016/j.forsciint.2017.09.008

33.BellED, DonatoAJ, Monson KL.Cerebrovasculardysfunction following subfailure axial stretch. Journal of the mechanical behavior of biomedical materials. 2017;65:627-633. https://doi.org/10.1016/j.jmbbm.2016.09.028

\section{Information about the authors:}

Shevcov A.V.; (Corresponding author); http://orcid.org/0000-0002-3666-6803; sportmedi@mail.ru; Lesgaft National State University of Physical Education, Sport, and Health; Institute of Adapted Physical Education, Physical Rehabilitation Department; Dekabristov St., 35 St. Petersburg, 190121, Russia.

Sashenkov S.L.; http://orcid.org/0000-0002-6007-1041; sashensl@yandex.ru; South Ural State Medical University, Normal Physiology Department ; Vorovskogo St., 64, Chelyabinsk, 454092, Russia.

Shibkova D.Z.; http://orcid.org/0000-0002-8583-6821; shibkova2006@mail.ru; South Ural State University (National Research University), Scientific and Research Center for Sports Science, Institute of Sport, Tourism and Service; Lenin Ave., 76 Chelyabinsk, 454080, Russia.

Bayguzhin P.A.; http://orcid.org/0000-0002-5092-0943; baiguznin@cspu.ru; South Ural State University (National Research University), Scientific and Research Center for Sports Science, Institute of Sport, Tourism and Service; Lenin Ave., 76 Chelyabinsk, 454080, Russia.

Cite this article as:

Shevtsov AV, Sashenkov SL, Shibkova DZ, Baiguzhin PA. Analysis of muscle tone and strength and cerebral blood flow in kickboxers. Pedagogics, psychology, medical-biological problems of physical training and sports, 2019;23(5):254-261. https://doi.org/10.15561/18189172.2019.0507

This is an Open Access article distributed under the terms of the Creative Commons Attribution License, which permits unrestricted use, distribution, and reproduction in any medium, provided the original work is properly cited (http://creativecommons.org/licenses/by/4.0/deed.en).

Received: 28.06.2019

Accepted: 25.07.2019; Published: 17.09.2019 